\title{
BIBLIOTECA ESCOLAR EM PERSPECTIVA: UM ESTUDO DE CASO ANALÍTICO, HISTÓRICO E SOCIAL SOBRE A BIBLIOTECA DO ATHENEU NORTE- RIOGRANDENSE
}

\author{
Igor Oliveira da Silva \\ Graduando em biblioteconomia - UFRN \\ igor_oliveira1993@hotmail.com
}

\section{Resumo}

\begin{abstract}
Objetiva realizar um panorama histórico e social da biblioteca de uma das escolas mais tradicionais da cidade do Natal, a do Colégio Estadual Atheneu Norte-rio-grandenses. Enfatiza a importância da biblioteca dessa instituição de ensino centenária para história da sociedade potiguar. Relata que a instituição tem encontrado diversos obstáculos, como por exemplo, a luta pela designação de um profissional bibliotecário, para viabilizar melhorias na prestação de serviço institucional aos alunos que a ela recorrem em busca de informações que venham agregar valores não apenas didáticos, mas culturais e sócias no decorrer se sua formação.
\end{abstract}

Palavras-chave: Biblioteca escolar. Atheneu Norte Rio-grandense. Bibliotecário. Leitura.

\section{INTRODUÇÃO}

As bibliotecas escolares exercem uma relevante função na sociedade. Sua definição deve ir além do conjunto de livros existente no acervo, pois ao se inserirem nos primeiros anos escolares tomam pra si a missão de formar leitores e usuários de informação. Estas, certamente, são competências importantes na formação de cidadãos.

A partir desse entendimento, foi empreendido estudo acerca do funcionalismo da biblioteca da Escola Atheneu Norte-riograndense. Num primeiro momento foi analisada sua função social em diferentes momentos da história, e posteriormente, tentou-se compreender a atual realidade da biblioteca e as principais dificuldades que ela tem enfrentado.

Nesse contexto, a promulgação da Lei federal 12.244/2010 que dispõe sobre a universalização das bibliotecas, tem possibilitado a criação de um novo afago para os diretores e alunos da instituição que anseiam por um profissional qualificado para atuar no ambiente da biblioteca escolar da instituição.

Para a realização deste trabalho foi realizada uma pesquisa junto a fontes primárias que mostram como era a realidade da biblioteca da instituição em outros tempos; em seguida, foi feita uma visita à instituição, além de uma entrevista com a servidora Aldemir Saraiva que já atuou na biblioteca e atualmente se dedica ao arquivo e ao memorial da instituição.

A partir das informações colhidas nessas fontes e na entrevista, foi possível realizar uma ponte, um estudo comparativo entre o antes e o agora, a fim de conhecer o funcionamento da biblioteca da instituição em diversos períodos.

\section{O ATHENEU NORTE- RIOGRANDENSE: BREVE HISTÓRICO E ATUAIS DESAFIOS}

A fim de atribuir melhor embasamento ao que será discutido neste trabalho, se faz necessário compreender o percurso histórico realizado pela escola desde a sua fundação até os dias atuais.

O Atheneu Norte-rio-grandense é uma das mais antigas instituições de ensino do Brasil; sua primeira sede localizava-se nas dependências do quartel militar do exército (atual Colégio Estadual Winston Churchill), tendo sua fundação ocorrido em 3 de 
fevereiro de 1834 - período em que o sistema monárquico ainda vigorava no Brasil - pelo então presidente de província Brasilio Quaresma Torreão, que veio a ser também o primeiro diretor da instituição.

Em 1859, a escola foi transferida para uma nova sede situada na Rua Junqueira Ayres (atual Rua Câmara Cascudo). Até o final do Império, a instituição recrutava apenas jovens do sexo masculino e continuou com esse mesmo modelo de seleção até o ano de 1954, quando mais uma vez é transferida para a atual sede, localizada no Bairro Petrópolis, e inaugurada pelo então governador Sílvio Pedrosa, em 11 de marco de 1954.

A escola do Atheneu é pioneira na educação do país e conhecida por formar gerações de jovens intelectuais da sociedade que, por vezes, vieram a se tornar personagens ilustres da cultura e política potiguar como por exemplo: Câmara Cascudo, Augusto Tavares de Lira, Pedro Velho D'Albuquerque Maranhão e João Café Filho. Médicos, como Onofre Lopes e até mesmo a bibliotecária e poetisa Zila Mamede, que mais tarde ao concluir o curso de Biblioteconomia no Rio de Janeiro, prestaria serviço à instituição, enquanto bibliotecária, dentre outras inúmeras personalidades que fizeram e fazem parte da história da instituição.

Atualmente a escola é composta por mais de mil alunos que se dividem em dois turnos (matutino e noturno); o corpo docente é formado por mais de 30 professores e os funcionários são apenas 10 , pois muitos já se aposentaram, outros vieram a falecer e o quadro de profissionais não é reposto.

A biblioteca está localizada na mesma sala que foi implantada em 1954 e não pode ser transferida para outro espaço, pois o prédio é tombado pelo Patrimônio Histórico do Estado.

A biblioteca escolar é considerada um espaço importante para uma educação de qualidade e para as práticas pedagógicas dos professores. Ela tem uma importante função na educação de crianças e jovens que estão em processo de formação e deve ser um espaço facilitador do acesso à informação, pois é através dela que os alunos buscam conhecimentos que contribuem com a aprendizagem.

\begin{abstract}
Ainda que não seja a salvação da escola e da educação pública, a biblioteca escolar pode ser um lugar privilegiado que contribua para a qualidade do ensino, ao promover práticas de leitura e acesso à informação de qualidade, integrando equipe técnica, professores e alunos à sua comunidade. (MOLLO. NÓBREGA, 2011, p.7)
\end{abstract}

Porém, nos últimos anos as bibliotecas escolares têm enfrentado sérias dificuldades em cumprir com um de seus papeis fundamentais que é a formação de novos leitores. Muitas delas carecem de um profissional bibliotecário para organizar o acervo e disponibilizar informações que contribuam com o processo de ensinoaprendizagem dos alunos a fim de atingir seus objetivos pedagógicos de incentivo à leitura, num trabalho conjunto com os professores.

O autor Waldeck Silva (1995) em sua obra intitulada Miséria da Biblioteca Escolar discorre sobre o panorama das bibliotecas escolares brasileiras. Segundo ele, existe um descaso para com esses espaços que não contam com apoio do Governo nem com as práticas de políticas públicas, além do silêncio de diversos grupos sociais, como pesquisadores e professores que se posicionam de forma omissa no combate a mudanças nessa estrutura existente.

O Atheneu Norte Rio-grandense não foge à regra, pois a carência de um profissional capacitado para melhor preparar seus alunos à leitura é evidente. Mas deve-se lembrar também que até o final do século $\mathrm{XX}$ a instituição formou verdadeiros leitores que foram inseridos na sociedade para produzir cultura, administrar o funcionalismo público e atuar nos mais diversos campos da sociedade.

Podemos perceber isso a partir dos registros encontrados em que mostram a luta dos alunos pelo acesso à biblioteca em um período em quem que não existia a diversidade nos meios de comunicações que temos hoje.

Um dos registos mais antigos, encontrado no tocante a biblioteca da instituição, data de 1891, período em que os republicanos estavam lutando para conquistar seus espaços dentro da sociedade potiguar. Isto frente às 
forças do conservadorismo que não tinham pretensão de contribuir com o desenvolvimento cultural e intelectual do Estado.

Este grupo de oposição à cultura chegou a impedir o acesso de professores, como o Dr. Antônio de Sousa e alunos pertencentes ao grêmio estudantil, a utilizarem a própria biblioteca da escola. O jornal A República, na tentativa de contribuir com a reabertura da biblioteca, tratou do descaso existente para com a biblioteca que caiu no desuso e no esquecimento.

Em uma das salas do Atheneu Riograndense viu-se, em tempos, estantes cheias de livros, cuja leitura franqueava-se ao público, e nesta terra fala-se já ter havido uma biblioteca. Hoje pairam estes livros, espalhados, por estantes particulares, a sala de leitura trancou-se, e a biblioteca, portanto, é uma simples recordação. Isso tudo é uma tristeza. (A República, 19/07/1981).

Mas adiante iremos perceber que, se a matéria do jornal A Republica de 1981 for publicada com os mesmos dizeres atualmente, a informação não estaria desatualizada, pois a realidade ainda é a mesma. No ano seguinte, 1982, o jornal A República, continua a tratar do descaso para com a biblioteca da instituição.

Em todos os países onde a Instrução pública é uma das primeiras, quando não é a principal preocupação dos governos, as bibliotecas são disseminadas por todos os pontos como meio eficaz da difusão do conhecimento. E nós que tanto gostamos de imitar a Europa, que tanto copiamos as suas instituições políticas, temo-nos até hoje preocupado tão pouco com a instrução que nem uma pequena biblioteca temos na capital. (A República, 04/06/1892, p.2).

A intenção do jornal era mostrar o caráter provinciano existente no estado, mesmo após a proclamação da República. A partir desses fragmentos, podemos perceber a importância que a biblioteca da instituição possuía, principalmente pelos Republicanos que tinham o objetivo de experimentar e difundir novas ideias e novos valores à cultura potiguar.
E importante destacar também que a biblioteca do Atheneu foi a primeira e única biblioteca de Natal, até a segunda metade do século XIX. Nesse período, a demanda por informações não vinha apenas dos alunos, mas por toda a sociedade que, de alguma forma, queria adquirir conhecimentos. Devido ao aumento no número de usuários que buscavam ter acesso aos livros da instituição, e a fim de ampliar o nível hierárquico da biblioteca, o governador Pedro Velho, elevou a biblioteca escolar do Atheneu, à biblioteca pública do estado do Rio Grande do Norte.

Quando Pedro Velho elevou a Biblioteca do Atheneu à categoria de Biblioteca Pública do Estado, definindo a manutenção desta como um dos fins do Atheneu, naquele momento estava reafirmando o papel que iria cumprir o Atheneu em seu governo, ou seja, Instituição posta a serviço do ensino e da cultura. (BARROS, p.4)

Assim, podemos ressaltar mais uma vez o valor atribuído à biblioteca através do esforço existente por parte da imprensa e do governador em contribuir com a formação de novos leitores, facilitando o acesso da população e possibilitando o desenvolvimento da política educacional no Estado do Rio Grande do Norte. A biblioteca escolar da instituição passou a ser mediadora, entre os livros e os usuários, fornecendo informações relevantes a formação do cidadão potiguar.

A prática da leitura é de fundamental importância em qualquer sociedade, seja ela desenvolvida ou não, e no Rio Grande do Norte, o Atheneu foi precursor na implantação desse hábito de forma eficiente e eficaz. Hoje colhe os frutos da semente plantada no passado, pois muitos dos seus alunos desenvolvem aptidões intelectuais e cognitivas através do contato com os livros que fornecem informações e transmite conhecimentos.

A leitura impulsiona a descoberta, a elaboração e a difusão do conhecimento, sendo possível, através dela, a aquisição de conhecimentos, a formação de valores, a reflexão, o pensamento crítico, Além disso, a leitura contribui para o convívio em sociedade, amplia os horizontes e proporciona a todos uma visão diferenciada 


\section{Anais do Encontro Paraibano de Biblioteca Escolar}

do mundo que os cerca (PEREIRA, 1998).

Com a inauguração do atual prédio em 1954, a biblioteca do Atheneu agregou uma personagem fundamental que estimulou e introduziu diversos alunos no mundo da prática de leitura. Trata-se da auxiliar de biblioteca Zila Mamede que contribuiu de forma significativa para organização e manutenção do acervo da instituição.

Segundo o advogado e ex-aluno Diógenes da Cunha Lima, a biblioteca não era tão grande, mas era bem cuidada e qualificada. A professora Wilma de Farias também resgata o caráter educativo que a biblioteca do Atheneu teve em sua formação: "O Atheneu teve para mim um duplo significado. Na biblioteca, pela oferta de livros que continham novas ideias, sedimentou-se o humanismo que retive e que me levou ao socialismo democrático; e, nos corredores, no pátio e nas eleições estudantis, a convivência." (Diário de Natal. 25/05/2005. p.8).

No ano seguinte, em 1955, ela se ausenta para cursar Biblioteconomia no Rio de Janeiro e retorna em 1957 para assumir a biblioteca do Atheneu como bibliotecária. $\mathrm{Na}$ instituição, ela realizou um excelente trabalho de incentivo à leitura e transmissão do conhecimento junto à comunidade escolar, porém ela só exerceu suas atividades até julho de 1962, quando passa a se dedicar à criação e elaboração das futuras instalações da Biblioteca do Estado e da Biblioteca Central da UFRN, que mais tarde recebia seu nome.

Com o decorrer dos anos, a educação pública no país deixou de ser tratada como prioridade e com a devida importância que merecia, alterando todo cenário da educação no Rio Grande do Norte e atingindo de forma direta, a biblioteca da instituição.

A Lei 2.885 , de 08 de abril de 1963, cria a Biblioteca do Estado Câmara Cascudo, pelo então governador Aluísio Alves, sendo inaugurada apenas em 26 de fevereiro de 1969. Com a criação da nova biblioteca do estado, os leitores dispõem de mais uma fonte de leitura, porém, a biblioteca do Atheneu perde visibilidade e volta a ser apenas uma biblioteca escolar que, com o passar do tempo, vai se tornando esquecida.

Segundo Naldemir Saraiva, que atualmente é uma das colaboradas da biblioteca e do arquivo da instituição, a biblioteca tem grandes dificuldades, pois faltam profissionais qualificados para exercerem a função de bibliotecário, além disso, o acervo é ultrapassado e não possui climatização adequada. A biblioteca não dispõe de ventiladores ou ar-condicionado, impossibilitando um atendimento de qualidade ao corpo discente. Ela ainda afirma que a biblioteca entrou em declínio a partir de 1990, quando as atribuições do bibliotecário foram atribuídas a pessoas não qualificadas, dificultando ainda mais as condições de um bom funcionamento.

É importante destacar que a atual realidade do Atheneu Norte-rio-grandense é a mesma de milhares de bibliotecas escolares espalhadas por todo Brasil.

Essa realidade é confirmada pela avaliação do diagnóstico do MEC (2008): as bibliotecas escolares públicas encontram-se numa situação crítica em questão de infraestrutura, acervo, suportes audiovisuais e informáticos e, em muitas delas, o profissional responsável por estas bibliotecas não é graduado em Biblioteconomia. Os estudos mostram ainda que há carência de profissionais bibliotecários e a ausência de concursos públicos para este cargo dificultam a utilização dos acervos e a formação de leitores nas escolas. (LEITE, 2013, p.2).

No ano de 2014, o Governo do Estado aplicou recursos com a finalidade de restaurar a escola que passava por um processo de deterioração, mas a realidade da biblioteca não foi modificada, principalmente no tocante ao acervo. Naldemir Saraiva afirma que:

Não tivemos até agora nem um melhoramento com relação ao acervo, móveis, estantes, etc. Nossa biblioteca está precisando urgentemente de conservação, um acervo mais moderno, pessoas em condições de trabalhar, pois temos pessoas que estão em readaptação, e não têm como assumir as funções, pois não possuem o conhecimento técnico de um funcionamento normal.

Nos dias de hoje, o acervo conta com 


\section{Anais do Encontro Paraibano de Biblioteca Escolar}

cerca de 8.000 exemplares de livros, além das enciclopédias, porém, esse acervo se encontra desatualizado, desorganizado e não está catalogado nem classificado, além do mal estado de conservação em que os livros se encontram.

Já o espaço físico, a biblioteca não é climatizada como mencionado anteriormente. As estantes são insuficientes e estão se deteriorando, algumas ficam encostadas na parede, pois não tem apoio, e em outras estantes é possível perceber as consequências do tempo com presença da ferrugem. A biblioteca não dispõe de equipamentos como computadores e os trabalhos são feito de forma manual.

A ausência de um profissional bibliotecário também é um grande obstáculo, pois os profissionais que estão atuando estão em readaptação. A presença de um profissional da área iria contribuir de forma significativa na resolução dos problemas que a biblioteca da instituição tem encontrado nos últimos anos.

Nesse contexto a Lei federal 12.244/10 representa para as bibliotecas escolares e para a classe de bibliotecários um avanço que só será possível através da união da classe em prol da aplicabilidade da lei.

Além da obrigatoriedade de bibliotecas escolares nas instituições de ensino com a presença de um exemplar para cada aluno, devemos observar também a necessidade de um profissional bibliotecário ${ }^{1}$ nas escolas. Para que isso aconteça, os conselhos de classe regionais e federal precisam se unir no combate a causa e na luta pela realização de concursos públicos que selecione esses profissionais para atuar nesses espaços a fim de realizar atividades de gestão dos acervos e acima de tudo promover a pratica da leitura nas instituições públicas e privadas de ensino do país.

Segundo o Conselho Regional de Biblioteconomia, CRB15, as lutas são constantes, mas precisam ser intensificadas

\footnotetext{
${ }^{1}$ Bibliotecário segundo a Lei 9.674/1998 são os profissionais liberais, pertencentes ao grupo 19 da Consolidação das Leis do Trabalho, e é privativa dos Bacharéis em Biblioteconomia.
}

Estamos com ações junto ao Ministério Público do Rio Grande do Norte e da Paraíba para que haja o cumprimento da lei 12.244. No Rio Grande do Norte as negociações já estão bastante avançadas. A maior barreira que estamos enfrentando é que o cargo de bibliotecário ainda não consta no quadro de educação dos municípios e estado. (CRB $15^{\mathrm{a}}$ Região)

O Departamento de Ciência da Informação da Universidade Federal do Rio Grande do Norte tem contribuído com a discussão através de uma ação de extensão denominada: Biblioteca Escolar: diálogos possíveis, coordenada pela professora Antônia de Freitas Neta. O projeto propõe uma mesa redonda a fim de debater a atual situação das bibliotecas escolares $^{2}$ e a aplicabilidade da Lei 12.244/10, com a participação do Conselho Federal e Regional de Biblioteconomia, dentre outras entidades que coordenam programas relacionados ao tema, como por exemplo, o Programa Biblioteca para Todos.

\section{CONSIDERAÇÕES FINAIS}

Diante dessa realidade, se faz necessário que a biblioteca do Atheneu Norte RioGrandense assuma o desafio junto às outras instituições em ensino do Estado no combate aos problemas existentes nas bibliotecas escolares. Aproveitando o ensejo da Lei federal 12.244/ 2010 que tem suscitado diversos debates sobre o papel das bibliotecas escolares na formação de novos leitores, essas discussões são importantes, pois ajuda a colocar as bibliotecas dentro do espaço de aprendizagem no ambiente escolar.

A mesma lei também possibilitando um grande avanço na qualidade da educação com a universalização das bibliotecas, pois mesmo no século XXI o acesso a bibliotecas, não é garantido a muitos brasileiros, além disso, ela se torna uma possibilidade para adequar às atividades do profissional bibliotecário que ainda luta para conquistar seu espaço dentro das bibliotecas das instituições de ensino não só no Rio Grande do Norte, mas como em

\footnotetext{
${ }^{2}$ Dentre as bibliotecas selecionadas, encontra-se a do Atheneu-Norte-rio-grandense
} 
todas as bibliotecas do país.

Desse modo, espera-se que a atual realidade em que a biblioteca do Atheneu se encontra seja modificada para que ela volte a ser um instrumento de educação e práticas de leitura eficaz na vida dos alunos que frequentam a instituição. Assim, ela voltará a realizar suas atividades, prestando um serviço de qualidade e formando leitores na sociedade potiguar, como um dia formou.

\section{REFERÊNCIAS}

BARROS, Eva Cristini Arruda Câmara. Atheneu Norte-rio-grandense: locus de desenvolvimento cultural da Natal republicana. Natal: Universidade Federal do Rio Grande do Norte. [s,d.].

CASCUDO, Luís da Câmara. História do Rio Grande do Norte. 2 ed. Natal: Fundação José Augusto; Rio de Janeiro: Achiamé, 1984.

LEITE, Suellen Moura et al. Lei 12.244/10: uma esperança para as bibliotecas brasileiras.
In: CONGRESSO BRASILEIRO DE BIBLIOTECONOMIA, DOCUMENTAÇÃO E CIÊNCIA DA INFORMAÇÃO, 25; Florianópolis, 2013. Anais...

LIMA, Diógenes da Cunha. Natal: biografia de uma cidade. Rio de Janeiro: Lidador, 1999.

MOLLO, Claúcia; NÓBREGA, Maria José. Biblioteca Escolar: que espaço é esse? Salto para o futuro. Ano XXI. Boletim 14. Outubro 2011.

MOURA, Pedro Rebouças de. Fatos da história do Rio Grande do Norte. Natal: CERN, 1986.

PEREIRA, Magda Chagas. Algumas considerações sobre leitura do hipertexto. R.ACB: biblioteconomia em Santa Catarina, Florianópolis, v.3, n.3, p.31-46, 1998.

SILVA, Waldeck Carneiro da. Miséria da biblioteca escolar. 3. ed. São Paulo, SP: Cortez, 2003. 